\title{
Translocação de molibdênio em plântulas de feijoeiro
}

Ireni Leitzke Carvalho, Fernanda da Motta Xavier, Michele Renata Revers Meneguzzo, Andréa Bicca Noguez Martins, Géri Eduardo Meneghello, Francisco Amaral Villela

Universidade Federal de Pelotas - UFPel, Pelotas, RS. E-mail: michelemeneguzzo@yahoo.com.br

\section{Resumo}

O objetivo do trabalho foi avaliar o efeito da aplicação de molibdênio via tratamento de sementes sobre a qualidade fisiológica de sementes de feijão (Phaseolus vulgaris L.) e o teor do elemento no tecido vegetal em diferentes estádios de desenvolvimento da plântula. Os tratamentos foram constituídos pela aplicação de molibdênio via sementes, utilizando solução de molibdato de amônio $\left(127 \mathrm{~g} \mathrm{~L}^{-1}\right)$, equivalentes a $0 ; 22 ; 44$;

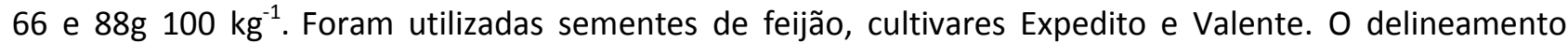
experimental foi inteiramente casualizado, com quatro repetições, avaliando-se separadamente cada uma das cultivares. A qualidade fisiológica das sementes foi avaliada pelos testes de germinação, primeira contagem da germinação, teste de frio, envelhecimento acelerado, emergência em campo, índice de velocidade de emergência, comprimento de plântulas e matéria seca de parte aérea e de raiz. Para a determinação do teor de molibdênio, realizou-se a semeadura em bandejas utilizando-se como substrato areia lavada. Aos 8, 10,12 e 14 dias após a semeadura realizou-se a coleta das plântulas. Determinaram-se a massa secadas plântulas e em espectrofotômetro UV-Vísivel a 405 nmo teor de molibdênio da parte aérea. Os dados obtidos permitem afirmar que há possibilidade de aplicar molibdênio em feijão, via tratamento de sementes, em doses de até $88 \mathrm{~g} 100 \mathrm{~kg}^{-1}$, sem causar prejuízos à qualidade fisiológica, tendo o teor de molibdênio nas plântulas aumentado linearmente com as respectivas doses aplicadas.

Palavras-chave: Phaseolus vulgaris L.; micronutriente; qualidade fisiológica.

\section{Translocation of molybden on feijoeiro plant}

\begin{abstract}
The objective of this work was to evaluate the effect of molybdenum application by seed treatment on the physiological quality of bean seeds (Phaseolus vulgaris L.) The treatments were constituted by the application of molybdenum via seeds, using ammonium molybdate solution $\left(127 \mathrm{~g} \mathrm{~L}^{-1}\right)$, equivalent to 0 ; 22 ;

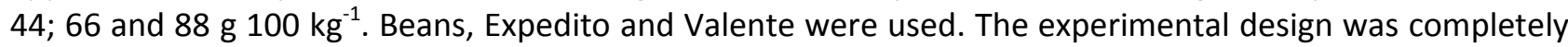
randomized, with four replicates, with each cultivar being evaluated separately. The physiological quality of the seeds was evaluated by germination, first germination count, cold test, accelerated aging, field emergence, emergence speed index, seedling length and dry matter of shoot and root. To determine the molybdenum content, sowing was carried out in trays using washed sand as the substrate. At 8, 10,12 and 14 days after sowing the seedlings were collected. The dry mass of the seedlings was determined and the UV-Visible spectrophotometer at $405 \mathrm{~nm}$ was the molybdenum content of the aerial part. The data obtained allow us to affirm that it is possible to apply molybdenum in beans, via seed treatment, in doses

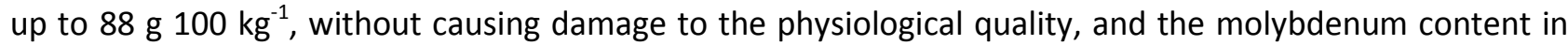
the seedlings increased linearly with the respective doses applied.
\end{abstract}

Keyswords: Phaseolus vulgaris L.; micronutrient; physiological quality. 


\section{Introdução}

O feijoeiro tem especial importância para a agricultura brasileira, por sua relevância na dieta da população, e por ser o Brasil um dos maiores produtores e consumidores de feijão do mundo (BARBOSA et al., 2010). Diante disso, um fator de extrema importância se dá ao uso de sementes de elevada qualidade.

Além do uso de sementes de alta qualidade é se duma importância proteger e até mesmo melhorar o desempenho das sementes. Isso pode ser realizado através do uso de produtos que proporcionam alterações morfológicas e fisiológicas nas planta, outros ainda apresentam a finalidade de nutrição como os micronutrientes.

Tratando-se de micronutrientes o molibdênio pertence ao grupo de micronutrientes essenciais para as plantas, embora seja um dos elementos minerais requeridos em menor quantidade para 0 crescimento normal das plantas. O molibdênio possui particular importância para 0 desenvolvimento do feijoeiro e demais espécies pertencentes à família Fabaceae, pois auxilia na nodulação que é indispensável ao processo de fixação simbiótica de nitrogênio. Sua principal ação, em termos de processos metabólicos, está restrita à participação em enzimas, tais como nitrogenase sendo essencial para a bactéria, redutase do nitrato e xantina oxidase/desidrogenase (FERREIRA; CRUZ, 1991; JACOB NETO; ROSSETO, 1998).

Para atingir alta produtividade, o feijoeiro requer quantidades de nitrogênio superiores a $100 \mathrm{~kg} \mathrm{ha}^{-1}$, que pode ser obtido a partir da fixação de nitrogênio atmosférico. No entanto, a eficiência desse processo biológico pode ser limitada por deficiências de micronutrientes, especialmente de molibdênio (CAMPO et al., 2009). A deficiência de molibdênio pode prejudicar a sobrevivência do Bradyrhizobium e, consequentemente, a nodulação e a fixação biológica do nitrogênio, diminuindo assim a produção (MORAES et al., 2008). O adequado suprimento de molibdênio pode influir positivamente na eficiência do Rhizobium no processo de fixação simbiótica de nitrogênio (ARAUJO et al., 1987).

Diversos trabalhos demonstraram aumento na produtividade de grãos de soja e feijão com o fornecimento de molibdênio, mediante aplicação no solo, nas sementes ou via foliar (LANTMANN, 2002; LEITE et al., 2007; BISCARO et al., 2009; ROCHA et al., 2011).

A concentração do molibdênio na planta é bastante variável, sendo comumente encontrada na faixa de 0,1 a $10 \mathrm{mg} \mathrm{kg}^{-1}$ de massa seca (MARTINÉZ et al., 1996). Para Dechene Nachtigall (2006), as concentrações adequadas para o crescimento das plantas variam entre $0,6 \mathrm{e}$ $10 \mathrm{mg} \mathrm{kg}^{-1}$ de massa seca. Todavia, Oliveira e Thung (1988) consideram a faixa adequada para o desenvolvimento da cultura de feijão variando de 0,4 a $1,4 \mathrm{mg} \mathrm{kg}^{-1}$ de massa seca.

A quantidade exigida de determinado micronutriente depende da cultura. A determinação de possíveis deficiências e/ou toxicidades pode ser realizada por diversos critérios, dentre eles o nível crítico. De acordo com Campo e Hungria (2002), existem acentuadas variações quanto ao nível crítico de molibdênio nos tecidos das plantas, pois a concentração do elemento químico na planta aumenta com a dose aplicada e, além disso, ocorre elevada capacidade de translocação do nutriente das folhas para as sementes.

A aplicação de molibdênio em sementes pode ser tão eficiente quanto às demais formas de aplicação (HAACH; PRIMIERI, 2012) e, além disso, apresenta vantagens econômicas, visto que o requerimento atinge quantidades $12 \mathrm{a} 25 \mathrm{~g} \mathrm{ha}^{-1}$, sendo que as pulverizações foliares demandam cerca de $80 \mathrm{~g} \mathrm{ha}^{-1}$ e a fertilização do solo $1.100 \mathrm{~g}$ $\mathrm{ha}^{-1}$ (LANTMANN, 2002). Segundo Santos et al. (2004), a aplicação do molibdênio nas sementes, por ocasião da semeadura, tende a ser mais eficiente que a aplicação foliar, por exigir doses menores para resultados semelhantes.

Por ser exigido em pequenas quantidades, é possível a aplicação juntamente ao tratamento de sementes. Porém, há deficiência de trabalhos que verifiquem a ocorrência ou não da absorção de molibdênio nas primeiras fases de desenvolvimento da planta. Assim, o objetivo do trabalho foi avaliar o efeito da aplicação de molibdênio via tratamento de sementes sobre a qualidade fisiológica de sementes de feijoeiro e o teor desse elemento químico no tecido vegetal em diferentes estádios de desenvolvimento da plântula.

\section{Material e Métodos}

O trabalho foi conduzido no Laboratório Didático de Análise de Sementes e na área experimental do Departamento de Fitotecnia da 
Faculdade de Agronomia "Eliseu Maciel", da Universidade Federal de Pelotas.

Foram utilizadas sementes de feijão preto, cultivares Expedito e Valente. Utilizou-se como fonte de molibdênio (Mo), o molibdato de amônio (solução $127 \mathrm{~g} \mathrm{~L}^{-1}$ ). Realizou-se o cálculo das doses para quantidade de $500 \mathrm{~g}$ de sementes (0; $1 ; 2 ; 3$ e $4 \mathrm{ml}$ da solução de molibdato de amônio), resultando em doses de Mo

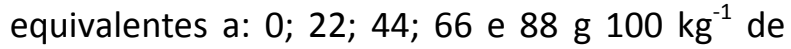
sementes. $O$ delineamento experimental foi inteiramente casualizado, com quatro repetições, avaliando-se separadamente cada uma das cultivares, em experimentos distintos.

A adesão do micronutriente às sementes foi realizada aplicando as doses do produto, sobre $500 \mathrm{~g}$ de sementes acondicionadas em sacos plásticos e agitadas vigorosamente até total distribuição sobre superfície das sementes, seguindo metodologia proposta por Nunes (2005). Em seguida, as sementes foram colocadas para secar em temperatura ambiente durante 24 horas. Para a avaliação do efeito das doses de molibdênio sobre a qualidade fisiológica das sementes de feijão foram aplicados os seguintes testes:

Germinação (G): realizado conforme as Regras para Análise de Sementes (Brasil, 2009), empregando quatro rolos de papel, cada um contendo 50 sementes, temperatura de $25^{\circ} \mathrm{C}$ e avaliações aos cinco e nove dias após o início do teste.

(PCG): consistiu na determinação da porcentagem de plântulas normais obtidas no quinto dia após a instalação do teste de germinação.

Teste de envelhecimento acelerado (EA): na condução seguiram-se as recomendações de Marcos Filho (2005), sendo as sementes distribuídas sobre telas de alumínio, fixadas no interior de caixas plásticas (tipo gerbox) contendo $40 \mathrm{~mL}$ de água destilada. As caixas foram fechadas e mantidas em câmara regulada a $41^{\circ} \mathrm{C}$, por 72 horas. Após esse período, as sementes foram colocadas para germinar, computando-se a porcentagem de plântulas normais no quinto dia após a instalação do teste.

Teste de frio (TF): foram utilizadas quatro repetições de 50 sementes seguindo metodologia do teste de germinação. Os rolos foram colocados em refrigerador a temperatura de 8 a $10^{\circ} \mathrm{C}$, durante 7 dias, e após, mantidos em germinador a temperatura de 25 -Ce realizada contagem das plântulas normais no quinto dia.

Comprimento da parte aérea (CPA) e da raiz (CR): foram utilizadas quatro repetições de 10 sementes, colocadas para germinar nas mesmas condições do teste de germinação. As sementes foram posicionadas de forma que a micrópila estivesse voltada para a parte inferior da folha de papel. Os rolos foram colocados na posição vertical em recipientes plásticos parcialmente imersos em coluna de água de $2 \mathrm{~cm}$, a fim de manter os rolos umedecidos. Os rolos e os respectivos recipientes foram envolvidos em saco plástico e mantidos em câmera com controle de temperatura, por nove dias a $25^{\circ} \mathrm{C}$. Ao final deste período, mensurou-se o comprimento das partes das plântulas normais (raiz primária e hipocótilo) utilizando-se uma régua graduada, em milímetros. Os resultados médios por plântula foram expressos em centímetros.

Massa seca da parte aérea (MSPA) e da raiz (MSR): foram utilizadas as partes aérea $\mathrm{e}$ radicular oriundas do teste de comprimento da parte aérea e da raiz, colocadas em estufa a $70 \circ \mathrm{C}$ com circulação de ar, durante $72 \mathrm{~h}$, sendo posteriormente pesadas em balança analítica. Os resultados foram expressos em mg.plântula ${ }^{-1}$, considerando-se pessoa massa média das partes.

Emergência de plântulas em campo (EC): quatro amostras de 50 sementes de cada tratamento foram semeadas em sulcos de um metro de comprimento, com espaçamento entre linhas de $20 \mathrm{~cm}$, cobertas com uma camada de solo de $3 \mathrm{~cm}$. A avaliação foi realizada aos 14 dias após a semeadura, computando-se o número de plântulas emergidas. Foram consideradas emergidas as plântulas que emitiram os cotilédones acima da superfície do solo.

Índice de velocidade de emergência (IVE): foi determinado em conjunto com o teste de emergência de plântulas em campo, contando-se diariamente o número de plântulas emergidas até a estabilização da emergência. No final do teste, empregando o número de plântulas emergidas a cada dia, calculou-se o IVE, empregando-se a fórmula proposta por Maguire (1962).

\section{Determinação do teor de molibdênio}

Obtenção da massa seca: As sementes, tratadas nas concentrações descritas anteriormente, foram colocadas para germinar em bandejas contendo areia lavada, e após 8,10 , 12 e 14 dias realizou-se coleta de tecido vegetal. 
As plântulas foram lavadas com água corrente $e$ deixadas de molho por dez minutos em detergente triton- x100 a 1\%, lavadas novamente em água corrente e água destilada. Após, com auxílio de um bisturi, separou-se a raiz e a parte aérea, procedendo a secagem separadamente em estufa a $70 \circ \mathrm{C}$ por $48 \mathrm{~h}$.

Digestão da amostra (adaptado de Tedesco et al., 1995)

Digestão a seco:0,25 g da parte aérea, massa seca, foi pesado em cadinho de porcelana de $50 \mathrm{~mL}$ e colocado em forno Mufla a $550^{\circ} \mathrm{C}$, para queima durante duas horas (obtenção de cinzas).

Digestão ácida: após resfriamento, foram adicionadas às cinzas, três gotas de água deionizada e $3 \mathrm{~mL}$ de ácido clorídrico $(\mathrm{HCl}) 6 \mathrm{M}$ e evaporados em placa aquecida $(110-120 \circ \mathrm{C})$ até secagem. Após, o precipitado foi diluído com $10 \mathrm{~mL}$ de $\mathrm{HCl} 0,125 \mathrm{M}$, e deixou-se decantar por 16 horas.

Preparação da amostra para leitura espectrofotométrica: Após, o tempo decorrido de decantação, foram retirados $3 \mathrm{~mL}$ do sobrenadante e transferidos para copo plástico descartável de $50 \mathrm{~mL}$. A esse volume foram adicionados $1 \mathrm{~mL}$ de fluoreto de amônio $\left(\mathrm{NH}_{4} \mathrm{~F}\right)$
0,25\%, $1 \mathrm{~mL}$ de água oxigenada $\left(\mathrm{H}_{2} \mathrm{O}_{2}\right)$ 0,02\% e 1 $\mathrm{mL}$ de iodeto de potássio (KI) $0,5 \%$. Dez minutos após a adição de $\mathrm{KI}$ foi determinada a concentração de Mo em espectrofotômetro UVVisível, Metrolab1700, a $405 \mathrm{~nm}$. Os resultados foram expressos em $\mathrm{mg} \mathrm{kg}^{-1}$ de massa seca (TEDESCO et al., 1995).

Delineamento experimental e procedimento estatístico: Os dados expressos em porcentagem sofreram transformação arco seno e foram submetidos à análise de variância e à regressão polinomial (MACHADO; CONCEIÇÃO, 2003), em nível de significância de 5\%.

\section{Resultados e Discussão}

Para ambas as cultivares e para todas as variáveis respostas de qualidade fisiológica, a análise de variância não mostrou efeito significativo das doses de molibdênio. Na Tabela 1 são apresentados os resultados de germinação, primeira contagem, teste de frio, envelhecimento acelerado, emergência em campo e índice de velocidade de emergência, em sementes de feijão, cultivares Valente e Expedito, tratadas com molibdênio.

Tabela 1. Germinação (G), primeira contagem da germinação (PCG), teste de frio (TF), envelhecimento acelerado (EA), emergência em campo (EC) e índice de velocidade de emergência (IVE) de feijão em função do tratamento de sementes com doses crescentes de molibdênio.

\begin{tabular}{|c|c|c|c|c|c|c|c|}
\hline Cultivar & $\begin{array}{l}\text { Doses Mo } \\
\left(\mathrm{g} 100 \mathrm{~kg}^{-1}\right)\end{array}$ & $\begin{array}{l}G \\
\text { (\%) }\end{array}$ & $\begin{array}{l}\text { PCG } \\
(\%)\end{array}$ & $\begin{array}{l}\text { TF } \\
\text { (\%) }\end{array}$ & $\begin{array}{l}\text { EA } \\
\text { (\%) }\end{array}$ & $\begin{array}{l}\text { EC } \\
\text { (\%) }\end{array}$ & IVE \\
\hline \multirow{5}{*}{ Valente } & 0 & 89 & 81 & 80 & 66 & 92 & 6,9 \\
\hline & 22 & 89 & 86 & 84 & 62 & 91 & 7,2 \\
\hline & 44 & 87 & 87 & 83 & 60 & 89 & 6,7 \\
\hline & 66 & 89 & 81 & 82 & 62 & 86 & 6,6 \\
\hline & 88 & 89 & 83 & 84 & 62 & 88 & 7,3 \\
\hline Média & & 89 & 84 & 83 & 62 & 90 & 6,9 \\
\hline \multirow{3}{*}{ CV (\%) } & & 4,1 & 3,9 & 3,8 & 3,1 & 7,6 & 6,6 \\
\hline & 0 & 94 & 83 & 93 & 88 & 93 & 7,7 \\
\hline & 22 & 95 & 84 & 91 & 87 & 97 & 8,2 \\
\hline \multirow[t]{3}{*}{ Expedito } & 44 & 94 & 83 & 91 & 87 & 96 & 8,7 \\
\hline & 66 & 96 & 86 & 92 & 85 & 94 & 8,3 \\
\hline & 88 & 90 & 80 & 87 & 83 & 94 & 7,7 \\
\hline Média & & 94 & 83 & 90 & 86 & 95 & 8,1 \\
\hline CV (\%) & & 2,3 & 5,0 & 3,2 & 3,7 & 5,3 & 6,6 \\
\hline
\end{tabular}

Observa-se que para as diferentes doses de molibdênio utilizadas, e em ambas as cultivares, ocorreu variações máximas de dois pontos percentuais (pp) na cultivar Valente e seis pp na cultivar Expedito, entre as doses que apresentaram maior e menor valor, respectivamente. Os valores indicam que as doses de molibdênio utilizadas não prejudicaram e nem estimularam a germinação de sementes de feijão. 
Quanto ao teste de primeira contagem, os resultados mostraram tendência semelhante aos da germinação, ou seja, não houve diferença significativa entre as doses. Observa-se que houve variação de seis $\mathrm{pp}$ nas duas cultivares entre as doses que apresentaram maior e menor valor, respectivamente. Esses resultados evidenciam que o tratamento de sementes com doses crescentes de molibdênio até $88 \mathrm{~g} 100 \mathrm{~kg}^{-1}$ ,não afetam o desempenho inicial de plântulas de feijão.

Em relação ao teste de frio as sementes da cultivar Expedito na dose (87\%), apresentou seis pp a menos que a dose zero (93\%). Por outro lado, para a cultivar Valente a variação máxima foi de quatro $\mathrm{pp}$.

$O$ teste de envelhecimento acelerado apresentou a mesma tendência do teste de frio, não apresentando diferença estatística pela variável analisada em função do. As sementes da cultivar Valente apresentaram média de $62 \%$ e a cultivar Expedito de $86 \%$ de vigor. Esta ocorrência pode ser atribuída ao fato de as sementes da cultivar Valente apresentarem maior incidência de danos mecânicos e de fungos. No teste do hipoclorito de sódio foi verificada uma incidência de danos mecânicos, 5\% para cultivar Expedito e de $25 \%$ para cultivar Valente. Durante a condução do teste de germinação observou-se a ocorrência de fungos nas amostras de semente da cultivar Valente, mostrando maior sensibilidade ao teste de envelhecimento acelerado. Por outro lado, as sementes da cultivar Expedito apresentaram desempenho fisiológico superior, ou seja, o período do estresse não afetou acentuadamente os resultados do teste. Em média, a redução relativamente ao teste de germinação atingiu 8 pp para a cultivar Expedito e $27 p p$ na cultivar Valente.

Para o teste de emergência em campo as sementes da cultivar Valente apresentaram maior variação entre as doses (6 pp) comparando-se o maior ( $92 \%$ na dose zero) e o menor resultado $\left(86 \%\right.$ na dose $\left.66 \mathrm{~g} 100 \mathrm{~kg}^{-1}\right)$, enquanto que para as demais doses aplicadas via tratamento de sementes a variação foi de no máximo $4 \mathrm{pp}$. Por outro lado, em relação à cultivar Expedito, a variação foi de 4 pp, entre o maior e o menor valor.

As tendências verificadas nos testes de vigor e de germinação das sementes não são discrepantes, verificando-se proximidade entre os valores de germinação e de emergência em campo, sugerindo que os tratamentos não interfeririam na qualidade das sementes de feijão, cultivares Expedito e Valente, e que as condições do campo foram favoráveis no período de condução do teste de emergência.

Embora tenham sido utilizadas doses


não foram observados efeitos prejudiciais à qualidade fisiológica das sementes de feijoeiro para ambas as cultivares.

De maneira similar, a avaliação do efeito de micronutrientes, dentre eles o molibdênio, realizada por Smiderle et al. (2008), aplicados por embebição em sementes de feijão sobre a qualidade fisiológica, não evidenciou alterações significativas na qualidade fisiológica das sementes.

Entretanto, esses resultados diferem dos alcançados por Oliveira et al. (2010) que apontam o Mo como um dos micronutrientes que mais contribuiu para aumentar a germinação e o vigor em sementes de mamona, após a embebição das sementes em solução contendo Mo, além de contribuir na redução da percentagem de sementes mortas. Pereira et al. (2012), concluíram que a qualidade fisiológica de milho é influenciada negativamente por doses crescentes de molibdênio na mistura com o fungicida líquido de suspensão concentrada carboxina+thiram sobre as sementes.

Os resultados da análise para as variáveis comprimento de parte aérea e de raiz e massa seca das partes aérea e raiz, utilizando no tratamento de sementes doses crescentes de Mo, estão apresentados na Tabela 2. A análise de variância não apresentou efeito significativo das doses de molibdênio, para as quatro variáveis respostas e para as duas cultivares. 
Tabela 2. Dados médios de comprimento de parte aérea (CPA), comprimento de raiz (CR), massa seca da parte aérea (MSPA) e massa seca da raiz (MSR), em plântulas de feijão das cultivares Valente e Expedito, tratadas com diferentes doses de molibdênio.

\begin{tabular}{|c|c|c|c|c|c|}
\hline Cultivar & $\begin{array}{l}\text { Doses Mo } \\
\left(\mathrm{g} \mathrm{100kg}^{-1}\right)\end{array}$ & $\begin{array}{l}\mathrm{CPA} \\
(\mathrm{cm}) \\
\end{array}$ & $\begin{array}{l}\text { CR } \\
(\mathrm{cm})\end{array}$ & $\begin{array}{l}\text { MSPA } \\
\text { (mg) }\end{array}$ & $\begin{array}{l}\text { MSR } \\
\text { (mg) }\end{array}$ \\
\hline \multirow{5}{*}{ Valente } & 0 & 14,2 & 10,0 & 54 & 17 \\
\hline & 22 & 14,2 & 10,3 & 54 & 16 \\
\hline & 44 & 15,0 & 10,4 & 59 & 17 \\
\hline & 66 & 15,7 & 10,3 & 59 & 17 \\
\hline & 88 & 13,8 & 10,7 & 54 & 16 \\
\hline Média & & 14,6 & 10,2 & 54 & 17 \\
\hline \multirow[t]{3}{*}{ CV (\%) } & & 8,2 & 12,2 & 8,3 & 11,7 \\
\hline & 0 & 12,5 & 11,8 & 54 & 17 \\
\hline & 22 & 12,0 & 11,3 & 52 & 15 \\
\hline \multirow[t]{3}{*}{ Expedito } & 44 & 13,1 & 12,4 & 52 & 17 \\
\hline & 66 & 11,9 & 12,9 & 57 & 14 \\
\hline & 88 & 11,5 & 10,8 & 53 & 15 \\
\hline Média & & 12,2 & 11,8 & 54 & 16 \\
\hline CV (\%) & & 9,1 & 8,9 & 5,5 & 11,7 \\
\hline
\end{tabular}

Esses resultados estão de acordo com os obtidos por Marcondes e Caires (2005) que também não observaram diferenças significativas nos resultados obtidos em função dos tratamentos, demonstrados pelas variáveis altura de plantas e produção de massa seca em soja, após a aplicação de Mo via sementes (zero e $48 \mathrm{~g}$ ha $\left.{ }^{-1}\right)$. A aplicação de doses crescentes de $\operatorname{Mo}(0$, 20,40, 80, 120 e $160 \mathrm{~g} \mathrm{ha}^{-1}$ ), via foliar, também não influenciaram na produção de biomassa da parte aérea e de raízes de soja e feijão (GUARESCHI; PERIN,2009). De maneira similar, Castro et al. (1994) concluíram que tratamento de sementes para o feijoeiro, com produtos contendo Co e Mo, acrescidos ou não com metionina ou vitamina $B 1$, não interferiram na massa seca das plantas.

Por outro lado, Oliveira et al. (2010) constataram em mamona que o Mo exerceu maior influência que os demais micronutrientes, sobre a produção de massa seca. De maneira geral, os dados obtidos para as sementes de feijão, cultivares Valente e Expedito, mostram que há possibilidade de aplicar molibdênio em feijão, via sementes, em doses de até $88 \mathrm{~g} 100 \mathrm{~kg}^{-}$
1, sem causar prejuízos à qualidade fisiológica, indicando assim, que esta cultura pode tolerar doses mais elevadas deste nutriente. É importante destacar que para a cultura da soja, Lantmann (2002) recomenda a aplicação de Mo via tratamento de sementes nas doses entre $12 \mathrm{e}$ $25 \mathrm{~g} \mathrm{ha}^{-1}$.

Na Figura 1 estão apresentadas as curvas de tendência, obtidos por análise de regressão polinomial para o teor de Mo na parte aérea de plântulas de feijoeiro. De acordo com os dados obtidos observa-se que o teor de Mo dos 8 aos 14 dias após semeadura, apresentaram tendência linear em relação às doses de Mo utilizadas no tratamento de sementes.

As plântulas, cv. Valente, apresentaram maior incremento na absorção do Mo com as doses aplicadas em comparação às da cultivar Expedito, em todas as avaliações, constatado pela maior inclinação da reta (maior coeficiente angular), porém sendo observado que o teor de Mo nas plântulas aumentou linearmente com as doses aplicadas nas duas cultivares. 
Figura 1. Teor de molibdênio na parte aérea de plântulas de feijoeiro em função de doses de molibdênio aplicado nas sementes de feijão para as cultivares Expedito e Valente.
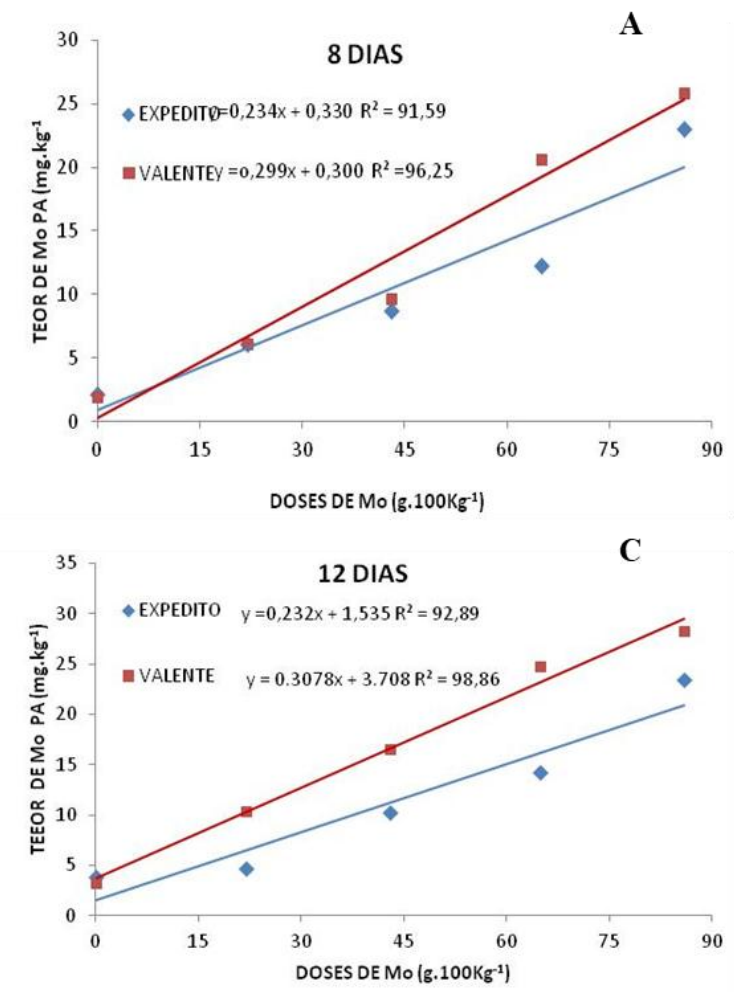

Aos 8 e 10 dias, após semeadura (Figura $1 \mathrm{~A}$ e1B), observa-se que a diferença de teor de Mo nas plântulas entre as cultivares foi de $1,5 \mathrm{mg}$ $\mathrm{kg}^{-1}$ de massa seca, enquanto que nas épocas de 10 a 14 dias essa diferença aumentou para $2,8 \mathrm{mg}$ $\mathrm{kg}^{-1}$, a cada incremento na dose de $22 \mathrm{~g} 100 \mathrm{~kg}^{-1}$ de sementes, indicando de maneira geral que as plântulas da cultivar Valente acumularam mais Mo do que as da cultivar Expedito. Vale ressaltar que as sementes da cultivar Valente apresentaram de modo geral, qualidade fisiológica inferior às sementes da cultivar Expedito (Tabela 1), sugerindo que o teor de Mo sofre variação com a cultivar.

Estes resultados corroboram com Rocha et al. (2011), que observaram aumento nos teores de Mo nas folhas de feijoeiro, durante o florescimento da cultura, aplicado via foliar em doses crescentes, aos 25 dias após emergência, promovendo um aumento linear deste elemento nas condições do estudo. Araújo et al. (2010) avaliando o efeito de doses crescentes de molibdênio, aplicado via foliar, na cultura do milho-pipoca visando aumentar o teor deste nutriente nas sementes, observaram que o teor de micronutriente nas folhas e nas sementes foi influenciado pela aplicação deste micronutriente, atingindo valores máximos com a maior dose aplicada.
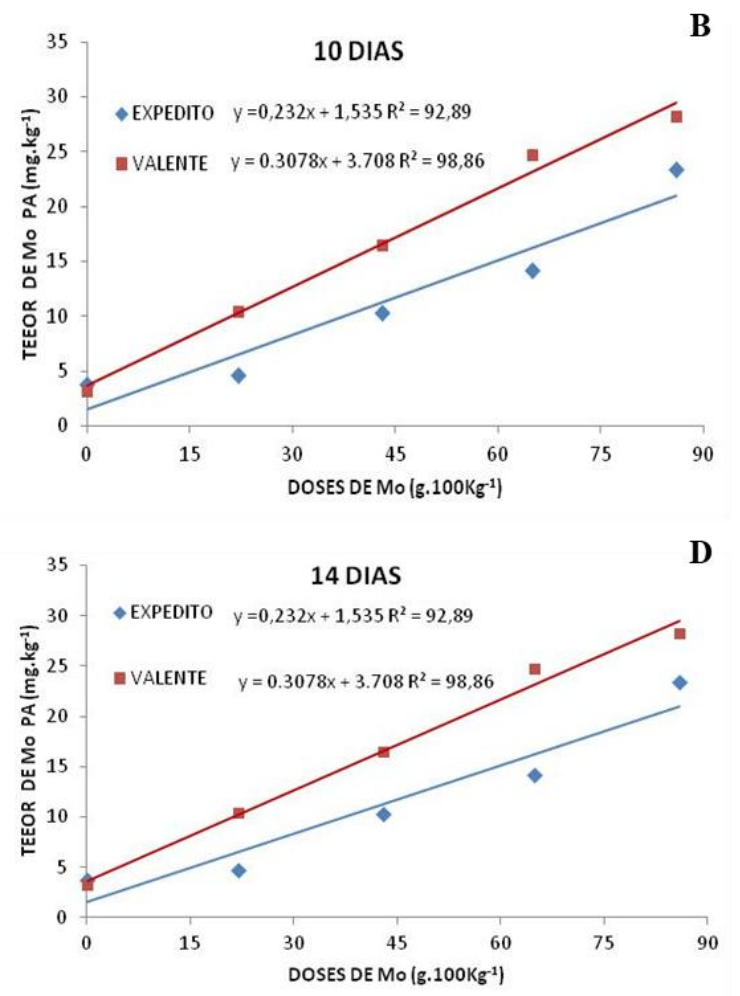

Avaliando o teor de molibdênio em folhas de feijão Pessoa et al. (2000) constataram que em folhas coletadas 50 dias após a semeadura, o teor de molibdênio aumentou de 0,49 para 0,95 $\mathrm{mg} \mathrm{kg}{ }^{-1}$, com a elevação das doses aplicadas via foliar. Entretanto, Castro et al. (1994) concluíram que os tratamentos de sementes para o feijoeiro, com produtos que contêm Co e Mo, acrescidos ou não de metionina ou vitamina $\mathrm{B} 1$, não interferiram nos teores de $\mathrm{N}, \mathrm{S}, \mathrm{Mo}$ e Co na parte aérea das plantas, avaliadas 30 dias após emergência.

Em estudo realizado na cultura da soja o autor verificou que a planta começa a absorver o Mo durante o período inicial de crescimento, aumenta sua concentração em toda extensão e reduz na fase de enchimento de grão (ISHIZUCA, 1982). Esse fato pode explicar o aumento de forma linear da concentração desse micronutriente nas condições do presente trabalho, pois as plântulas estavam na fase inicial de desenvolvimento.

Os resultados alcançados no presente trabalho são promissores, levando em conta a possibilidade de aplicação de molibdênio, via tratamento de sementes de feijão, em doses de

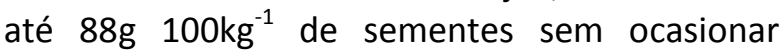
efeitos deletérios à qualidade fisiológica das sementes. As doses de molibdênio utilizadas não 
foram suficientes para atingir o máximo acúmulo deste micronutriente na parte aérea de plântulas de feijoeiro, no intervalo avaliado. Assim, o aumento do teor de Mo nas plântulas pode ocasionara correção de eventuais deficiências em solos carentes neste nutriente.

\section{Conclusões}

A aplicação de molibdênio via tratamento de sementes, em doses de até $88 \mathrm{~g} 100 \mathrm{~kg}^{-1}$ não causaram prejuízos à qualidade fisiológica de sementes de feijão.

O teor de molibdênio nas plântulas de feijão cresceu linearmente com o aumento das doses aplicadas na semente.

\section{Referências}

ANTMANN, A. F. Nutrição e produtividade da soja com molibdênio e cobalto. Artigos Embrapa, Coletânea Rumos \& Debates, 2002. Disponível em: www.embrapa.org.br. Acessado em: mar. 2018.

ARAUJO, G. A. A.; FONTES, L.A.N.; AMARAL, F.A.L. CONDÊ, A.R. Influência domolibdênio e do nitrogênio sobre duas variedades de feijão (Phaseolus vulgaris L.). Revista Ceres, Viçosa, v.34, n.2, p.333-339, 1987.

ARAUJO, G. A. A.; TEIXEIRA, A. R.; MIRANDA, G. V.; GALVÃO, J. C. C.; ROCHA, P. R. R. Produtividade e qualidade fisiológica de sementes de milho pipoca submetido à aplicação foliar de molibdênio. Scientia Agraria, Curitiba, v.11, n.3, p.231-237, 2010. https://doi.org/10.5380/rsa.v11i3.17509

BARBOSA, G. F.; ARF, O.; NASCIMENTO, M. S.; BUZETTI, S.; FREDDI, O. S. Nitrogênio em cobertura e molibdênio foliar no feijoeiro de inverno. Acta Scientiarum. Agronomy, v. 32, n. 1, p.117-123, 2010. http://dx.doi.org/10.4025/actasciagron.v32i1.160 $\underline{5}$

BISCARO, G. A.; GOULART JUNIOR, S. A. R.; SORATTO, R. P.; FREITAS JÚNIOR, N. A.; MOTOMIYA, A. V. A.; CALADO FILHO, G. C. Molibdênio via semente e nitrogênio em cobertura no feijoeiro irrigado em solo de cerrado. Ciência Agrotecnologia, Lavras, v. 33, n.5, p.1280-1287, 2009. http://dx.doi.org/10.1590/S1413$\underline{70542009000500012}$
BRASIL. Ministério da Agricultura e Reforma Agrária. Regras para análise de sementes. Brasília: SNAD/CLAV, 2009. 395p.

CAMPO, R. J; ARAUJO, R. S.; HUNGRIA, M.; Molybdenum-enriched soybean seeds enhance $\mathrm{N}$ accumulation, seed yield, and seed protein content in Brazil. Field Crops Research, v.110, n.3, 2009.

\section{https://doi.org/10.1016/j.fcr.2008.09.001}

CAMPO, R. J.; HUNGRIA, M. Importância dos micronutrientes na fixação biológica do nitrogênio. Informações Agronômicas, n.98, 2002.

CASTRO, A. M. C.; BOARETTO, A. E.; NAKAGAWA, J. Tratamento de sementes de feijoeiro (Phaseolus vulgaris I.) com molibdênio, cobalto, metionina e vitamina b1. Revista Brasileira de Sementes, v.16, n.1, p.26-30, 1994. https://doi.org/10.17801/0101-

3122/rbs.v16n1p26-30

DECHEN, A.R.; NACHTIGALL, G.R. Micronutrientes. In: FERNANDES, M.S. (Ed.). Nutrição mineral de plantas. Viçosa: SBCS, 2006. p. 328-354.

FERREIRA, M.E.; CRUZ, M.C.P. Cobre. In: FERREIRA, M.E.; CRUZ, M.C.P. (Eds.). Micronutrientes na agricultura. Piracicaba: Potafos, 1991. p. 131-157.

GUARESCHI, R.F.; PERIN, A. Efeito do molibdênio nas culturas da soja e do feijão via adubação foliar. Global Science and Technology, v.2, n.3, p.08-15, 2009.

HAACH, R.; PRIMIERI, C. Aplicação de zinco e molibdênio em tratamento de sementes e via foliar na cultura da soja. Cultivando o Saber, Cascavel, v.5, n.1, p.21-29, 2012.

ISHIZUCA, J. Characteristics of molybdenum absorption and translocation in soybean plants. Soil Science \& Plant Nutrition, v.28, n.1, p.63-77, 1982.

https://doi.org/10.1080/00380768.1982.1043237 $\underline{2}$

JACOB NETO, J.; ROSSETO, C. A. V. Concentração de nutrientes nas sementes: 0 papel do 
molibdênio, Floresta e Ambiente, Seropédica,v.5, n.1, p.171-183, 1998.

LEITE, U.T.; ARAÚJO, G. A. A.; MIRANDA, G.V.; VIEIRA, R.F.; CARNEIRO, J.E.S.; PIRES, A.A. Rendimento de grãos e componentes de rendimento do feijoeiro em função da aplicação foliar de doses crescentes de molibdênio. Acta Scientiarum Agronomy, Maringá, v.29, p. 113120, 2007.

MACHADO, A.A.; CONCEIÇÃO, A.R. Sistema de análise de estatística para windows. WinstaT. Versão 2.0. Pelotas: Universidade Federal de Pelotas, 2003.

MAGUIRE, J. D. Speed of germination - aid in selection aid evolution for seedling emergence and vigor. Crop Science, Madison, v.2, n.2, p.176177 , 1962. https://doi.org/10.2135/cropsci1962.0011183X0 $\underline{00200020033 x}$

MARCONDES, J. A. P.; CAIRES, E. F. Aplicação de molibdênio e cobalto na semente para cultivo da soja. Bragantia, Campinas, v.64, n.4, p.687-694, $2005 . \quad$ https://doi.org/10.1590/S0006$\underline{87052005000400019}$

MARCOS FILHO, J. Fisiologia de sementes de plantas cultivadas. Piracicaba: FEALQ, 2005.

MARTINEZ, E. L; BARRACHINA, A. C.; CARBONELL, F. B.; POZO, M. A.; GRCIA, M. A.; BENEYTO, J. M. Molybdenum uptake, distribution end acumulation in bean plants. Freserius Envirbull, v.5, p.73-78, 1996.

MORAES, L. M. F.; LANA, R. M. Q.; MENDES, C.; MENDES, E.; MONTEIRO, A.; ALVES, J. F.; Redistribuição de molibdênio aplicado via foliar em diferentes épocas na cultura da soja. Ciência e Agrotecnologia, Lavras, v.32, n.5, p.1496-1502, 2008.

NUNES, J.C. Tratamento de semente - qualidade e fatores que podem afetar a sua performance em laboratório. Syngenta Proteção de Cultivos, 2005. 16 p.

OLIVEIRA, I.P.; THUNG, M.D.T. Nutrição mineral. In: ZIMMERMANN, M.J.O.; ROCHA, M.; YAMADA, T. (Eds.). Cultura do feijoeiro: fatores que afetam a produtividade. Piracicaba, POTAFOS, 1988. p.175-212.

OLIVEIRA, R. H.; SOUZA, M. J. L.; MORAES, O. M.; GUIMARÃES, B. V. C.; PEREIRA JUNIOR, H. A. Potencial fisiológico de sementes de mamona tratadas com micronutrientes. Acta Scientiarum. Agronomy, Maringá, v. 32, n. 4, p. 701-707, 2010. https://doi.org/10.4025/actasciagron.v32i4.4829

PEREIRA, F. R. S.; BRACHTVOGEL,E. L.; CRUZ, S. C. S.; BICUDO, S. J.; MACHADO,C. G.; PEREIRA, J. C. Qualidade fisiológica de sementes de milho tratadas com molibdênio. Revista Brasileira de Sementes, Londrina, v.34,n.3, 2012.

PESSOA, A.C.S.; RIBEIRO, A.C.; CHAGAS, J.M.; CASSINI, S.T.A. Concentração foliar de molibdênio e exportação de nutrientes pelo feijoeiro "Ouro Negro" em resposta à adubação foliar com molibdênio. Revista Brasileira de Ciência do Solo, Campinas, v.24, p.75-84, 2000. https://doi.org/10.1590/S010006832000000100010

ROCHA,P. R. R.; ARAÚJO, G. A. A.;CARNEIRO, J. E. S.; CECON, P. R.; LIMA, T, C. Adubação molíbdica na cultura do feijão nos sistemas de plantio direto e convencional. Revista Caatinga, Mossoró, v.24,n.2, p.9-17, 2011.

SANTOS, L. P.; VIEIRA, C.; SEDIYAMA, T.; SEDIYAMA, C. S. Adubação nitrogenada e mobilíbdica da soja: Influência sobre a maturação, índice de colheita e peso de mil sementes. Revista Ceres, v.51, n. 296, p.429-444, 2004.

SMIDERLE, O. J.; MIGUEL, M. H.; CARVALHO, M. V.; CÍCERO, S. M. Tratamento de feijão com micronutrientes: Embebição e qualidade fisiológica. Revista Agro@mbiente on-line, Boa Vista, v.2, n.1, p.1982-8470, 2008. http://dx.doi.org/10.18227/1982-

8470ragro.v2i1.156

TEDESCO, M. J., GIANELLO, C., BISSANI, C. A., BOHNEN, H., VOLKWEISS, S. J. Análises de solo, plantas e outros materiais. 2. ed. Porto Alegre, Universidade Federal do Rio Grande do Sul, 1995. 114 p. (Boletim Técnico, 5). 